\title{
Transient Behaviour of Heat Exchangers Under Inlet Perturbations
}

\author{
Shahram Fotowat ${ }^{1}$, Serena Askar ${ }^{1}$, Amir Fartaj $^{1}$ \\ ${ }^{1}$ Department of Mechanical Automotive and Materials Engineering, University of Windsor \\ 401 Sunset Avenue, Windsor, Ontario, Canada \\ fotowat@uwindsor.ca; askars@uwindsor.ca \\ fartaj@uwindsor.ca
}

\begin{abstract}
The aim of this investigation is to characterize the transient performance of different heat exchangers for their design and efficient control. This paper explored the effect of inlet mass flow rate and temperature step variations on the dynamic response of a conventional and a minichannel heat exchanger. The work was also extended to include a comparison between these two heat exchangers when both subjected to sudden changes in the liquid inlet conditions. A comprehensive, well-equipped, and large-scale experimental setup was designed and assembled to examine the thermal performance of different heat exchangers under steady and transient changes. At the early stage of a step change, the influence of changing mass flow and inlet temperature of the hot fluid on the response time is found significant while, this effect diminishes as the system approaches steady state. The hot liquid inlet conditions change of mass flow and temperature have more significant effect on the minichannel liquid outlet temperature when compared to the conventional heat exchanger. The reported results can find an application in the design and selection of a cross flow heat exchanger used in thermal management systems such as in automotive industry where compact heat exchanger is required for size and weight reduction.
\end{abstract}

Keywords: Transient performance; Response time; Step change; Heat exchanger

\section{Introduction}

The heat exchanger geometry plays a significant role in the design process of heat exchangers and their thermal performance evaluations. Different approaches have been under investigation to enhance the heat exchanger performance including improving their current design and introducing alternative geometries. In the light of the search for reduced size, weight, and energy efficiency as well as improved performance, a micichannel heat exchanger which has an enhanced surface area to volume ratio was presented. Various studies on heat exchangers of different configurations have been completed at steady state conditions [1-2]. However, in real life scenario, heat exchangers undergo transient variations. An automotive thermostat is a great example of inlet conditions fluctuations. The opening and the closing of the thermostat valve creates a variation in the coolant temperature entering the radiator and results in transient mode. For this purpose, it is very important to characterize the dynamic behavior of heat exchangers for their effective control. Different forms of transient fluctuations were applied by researchers such as step, ramp, and exponential. However, the common type of transient variation that can be found in real applications is approximated nearly by a step function [3]. Heat exchangers do not respond rapidly to perturbations in fluid inlet mass flow rate or temperature, instead a period of time is needed to reach the steady state after any change. Another reason to consider transient analysis is that fluctuations in inlet conditions create a variation in the heat exchanger response, and consequently undesirable effect on the process [4].

Stermole and Larson investigated the dynamic response of flow in heat exchangers [5]. They used a double pipe counter current heat exchanger for their experimental and theoretical analyses. They found that as the flow rate varies, the system behaved linearly for such an exchanger. The transient behavior of the heat exchanger in a Marnoch heat engine was studied by Prashant Regulagadda [6]. He examined this behavior using laminar and turbulent flows. A model is created to predict the temperature of the working fluid for a parallel flow heat exchanger with a step change in mass flow rate. Syed and Idem [7] used a minimum capacity rate fluid in a single pass cross flow heat exchanger for step changes in temperature. They used a numerical analysis based on the finite difference method to present the prediction of changing the grid size and time steps. They found that transient time was decreased with smaller capacity rate ratio for both fluids outlet temperatures. The cases of minimum and maximum capacity rate ratios were compared, and the smaller temperature change was found in the maximum capacity rate ratio compared to the minimum. The motivation of this work is the lack of the experimental data and 
research involving transient behavior of heat exchangers due to wide range of inlet condition fluctuations in the hot liquid. The objective of this research is to determine the factors that influence the transient response and study the heat exchanger behavior under different perturbations of inlet liquid conditions. A step change is applied on the liquid side inlet conditions of mass flow rate and temperature to an unmixed-unmixed cross flow heat exchanger while keeping the other inlet parameters constant. A wide range of step changes in mass flow 0.5 to 2.5 and in inlet temperature 1.5 to 3.5 are applied. The main observations and conclusions are discussed and summarized in this work. The reported results explain the behavior of different heat exchangers under the same perturbations applied to them and the effect of different geometry on the response time of the heat exchanger.

\section{Experimental setup}

A unique and large-scale experimental setup is designed and assembled to examine the thermal performance of different heat exchangers under steady and transient changes. This setup accommodates accurate control of the fluid inlet parameters to accomplish transient variations in inlet conditions of the working fluids. The schematic of the main components of the experimental setup is demonstrated in Figure 1.

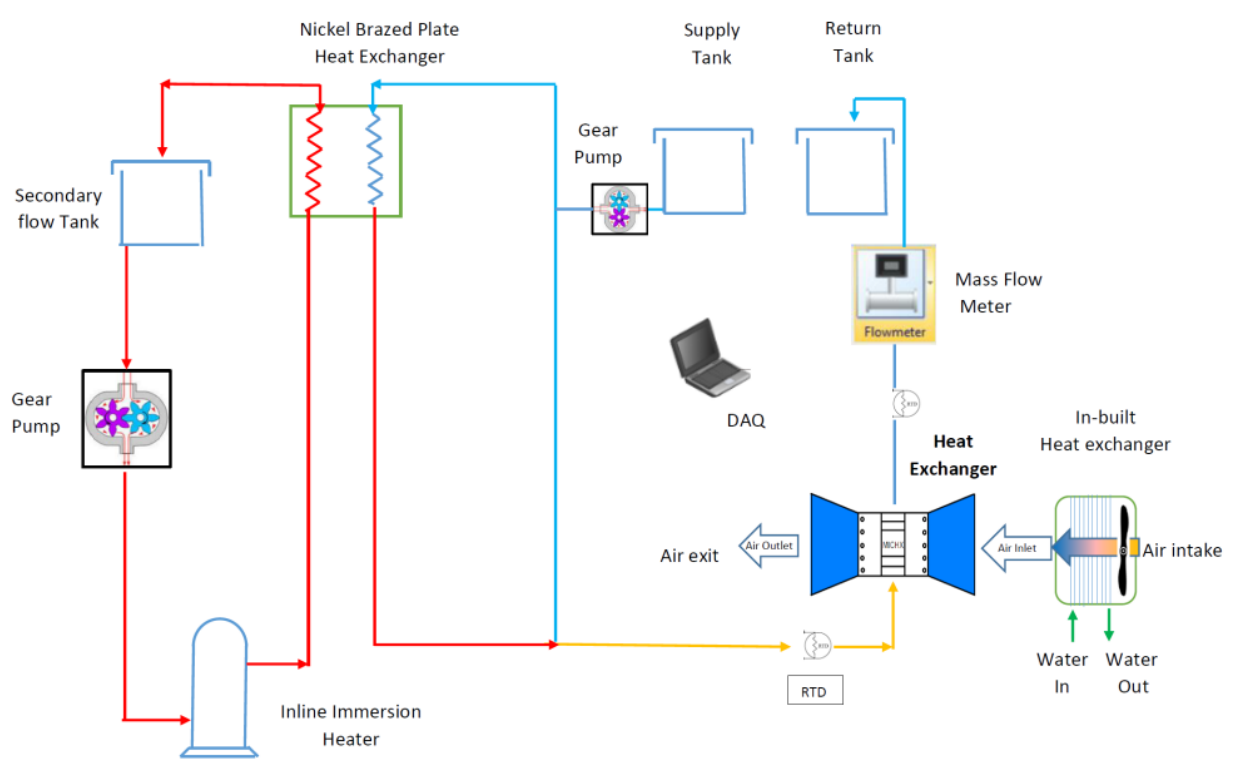

Fig. 1: Schematic diagram of the experimental set up.

\section{Governing equations}

Assumptions considered for the current analysis are as follows:

- Heat transfer from or to the environment is negligible

- Axial heat conduction in the heat exchanger is negligible

- The fluids do not undergo a phase change

$$
T_{h, o}^{*}=\frac{T_{h, o}(\mathrm{t})-T_{c, i}}{T_{h, i}-T_{c, i}}
$$

The dimensionless temperature at the steady state condition is determined as:

$$
T_{h, o}^{*, \infty}=\frac{T_{h, o}^{S S}\left(t^{S S}\right)-T_{c, i}}{T_{h, i}-T_{c, i}}
$$


The residence time defines the time that takes the hot liquid to enter and leave the heat exchanger and is presented as follows,

$$
t_{\text {res }}=\frac{n A_{c} L}{\dot{\forall}}=\frac{L}{V}
$$

A dimensionless form of time is presented by dividing time over the residence time, for the generalization purpose as,

$$
t^{*}=\frac{t}{t_{\text {res }}}=\frac{V_{c}}{L} t
$$

\section{Results and discussion}

This work discussed the transient performance of both minichannel and conventional heat exchangers when both subjected to sudden changes in liquid side inlet conditions. For the first case, only the hot fluid inlet temperature was changed to steps of 1.5 to 3.5 and for the second case the hot fluid mass flow rate was varied in the steps of 0.5 to 2.5 while the other fluids inlet conditions were kept constant. The temperature step change was denoted by TR indicating the temperature ratio while the mass flow rate ratio was presented by MR.

\subsection{Conventional heat exchanger results}

\subsubsection{Effect of MR on dimensionless outlet liquid temperature response}

The effect of the liquid mass flow rate steps on the dimensionless hot fluids outlet temperatures for the conventional heat exchanger is presented in Figure 2. A constant air inlet temperature of $13^{\circ} \mathrm{C}$ and mass flow rate of $0.222 \mathrm{~kg} / \mathrm{s}$ are considered with constant hot liquid temperature of $70^{\circ} \mathrm{C}$ when the hot fluid mass flow steps changed from 0.5 to 2.5 . The figure demonstrated how fast the mass flow step changes are approaching the steady state condition. A faster response time, the time it takes to undergo from one steady state to another steady state, is found at higher MR. This could be explained by the fact that higher mass flow rate causes higher heat transfer rate results in faster response time.

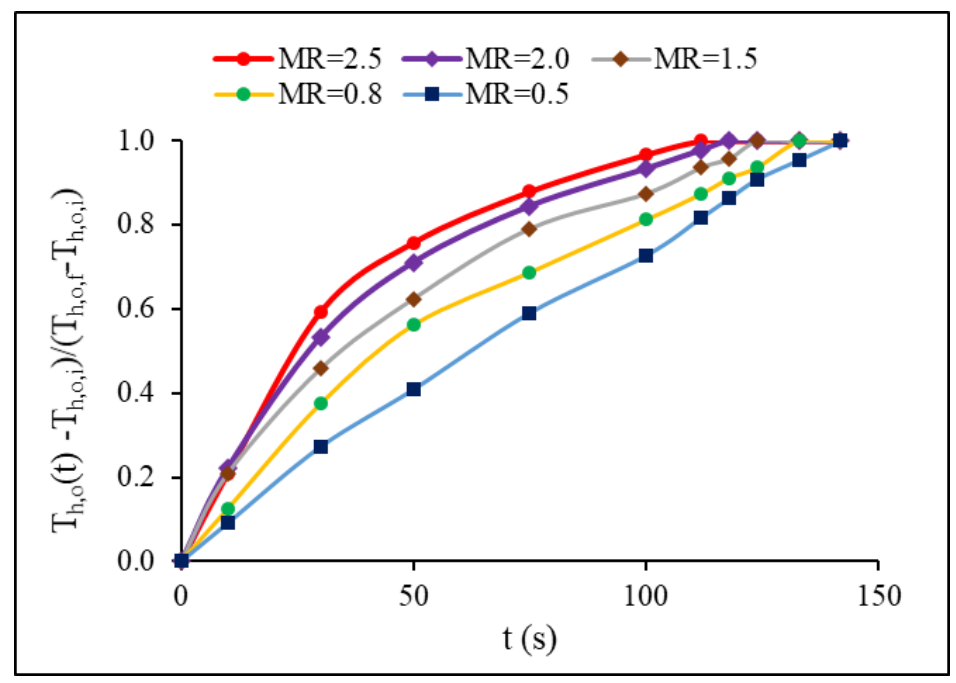

Fig. 2: Hot fluid temperature response at different liquid MR.

\subsubsection{Effect of TR on dimensionless outlet liquid temperature response}

Figure 3 illustrates the effect of the liquid temperature steps on the dimensionless hot fluid outlet temperature for the conventional heat exchanger. The liquid inlet temperature steps varied from 1.5 to 3.5 in steps of 0.5 while the other fluids conditions were kept constant. The inlet temperature step variations have a major effect on the liquid outlet response at the initial time of the change and negligible effect at the end of the change. The rate of change in the hot fluid outlet temperature increased with the increase of the inlet temperature steps. This can be interpreted by increase in temperature gradient between 
the liquid and heat exchanger wall that results in higher heat transfer rate and shorter response time. A non-linear trend is found for the hot fluid outlet temperature at initial transition phase and lower TR and changes to linear as it approaches the steady state.

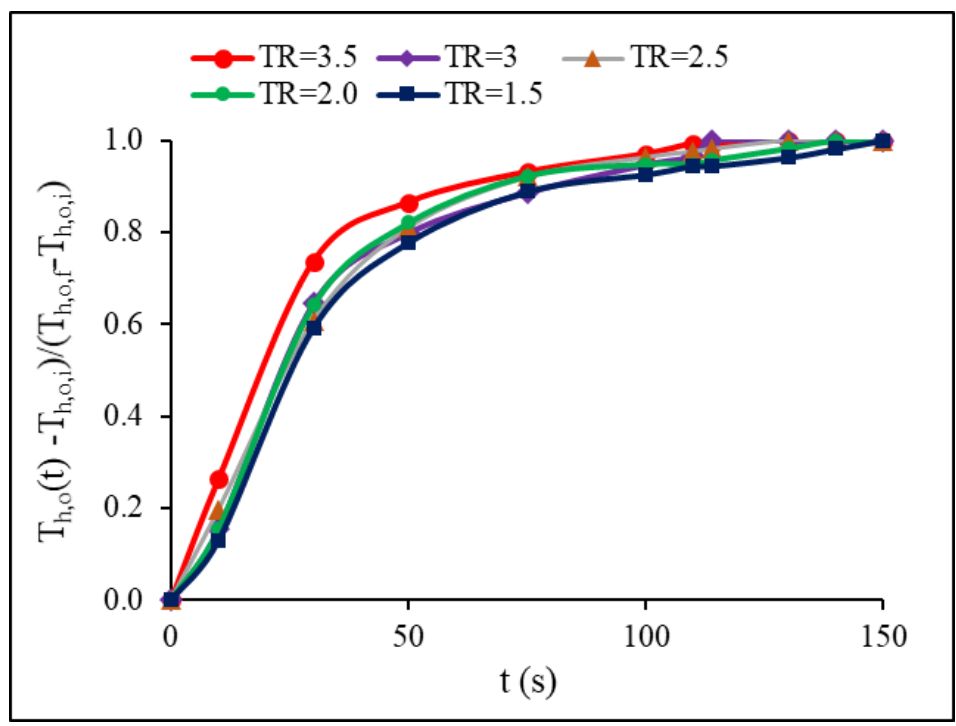

Fig. 3: Hot fluid temperature response at different liquid TR.

\subsubsection{Comparison of TR and MR on the hot fluid outlet temperature response}

The effect of temperature and mass flow step changes on the hot liquid outlet temperature is presented in Figure 4. The rate of change in the outlet temperature is higher as the mass flow and temperature steps increase. The response time at lower steps is found shorter compared to higher steps for both MR and TR changes. In addition, the response time is shorter for MR compared to TR for the same operating condition. Because higher liquid mass flow rate results in higher Reynolds number that causes more heat transfer rate and shorter response time.

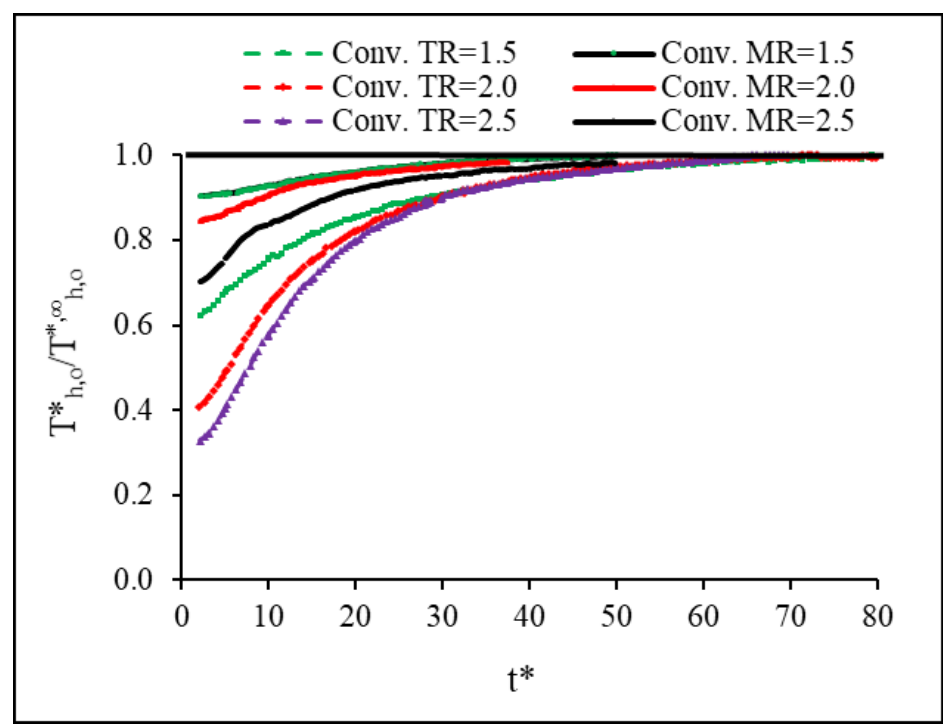

Fig. 4: Hot fluid outlet temperature response at different TR and MR variations. 


\subsection{Comparison of the minichannel and conventional heat exchangers results 4.2.1. Hot fluid outlet temperature responses comparison}

The effect of mass flow step changes on the hot liquid outlet temperature for the two heat exchangers is demonstrated in Figure 5. When comparing the two heat exchangers, it is noticed that the effect of varying the liquid mass flow rate in the minichannel heat exchanger is more significant than in the conventional heat exchanger. Another observation is the shorter response time of the minichannel heat exchanger compared to the conventional heat exchanger considering the same operating condition. This is due to higher liquid heat transfer coefficient in the MICHX causes faster response time.

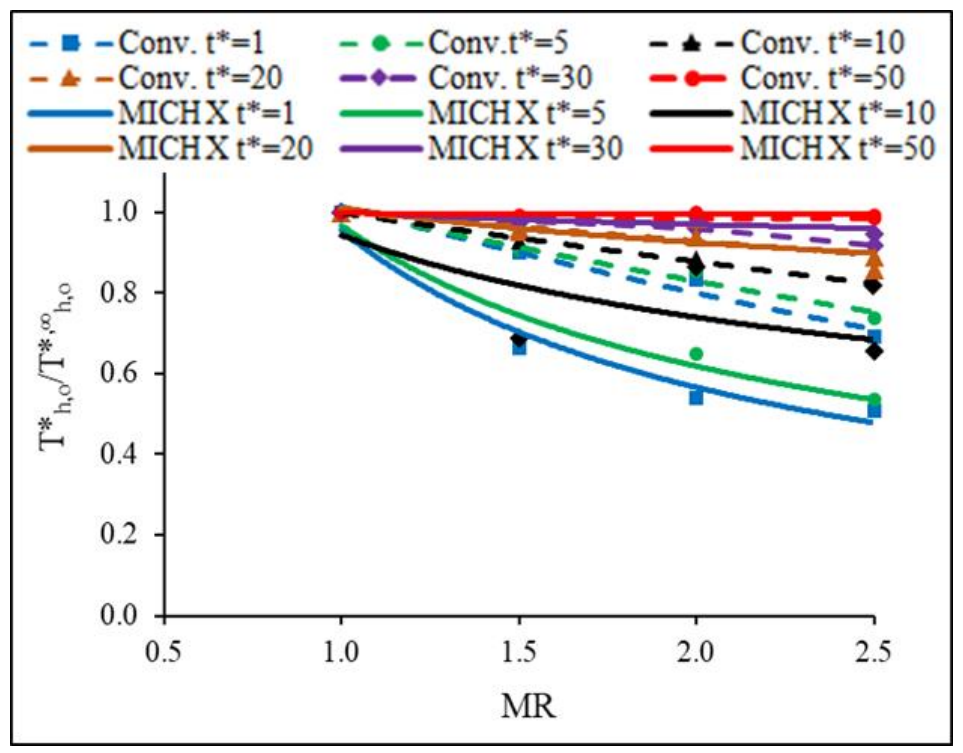

Fig. 5: Comparison of heat exchangers liquid outlet temperature response at different MR.

\section{Conclusion}

Experiments were performed on cross flow minichannel and conventional heat exchangers subjected to different step changes in the hot fluid inlet temperature and mass flow rate. The changes in the flow rate considered for this study varied from 1 to 2.5 and for inlet liquid temperature from 1 to 3.5. The main findings are listed below,

- At the early stage of a step variation, the change of hot liquid mass flow rate and inlet temperature plays a significant role on the response time while, this influence diminishes as the system approaches steady state.

- Response time is shorter for higher step changes in both MR and TR

- Response time is faster for MR than TR for the same step variation

- Transient behaviour of MICHX is superior to conventional heat exchanger as a benchmark under the same inlet operating condition.

\section{Acknowledgements}

This investigation is supported by the Natural Sciences and Engineering Research Council of Canada provided at the University of Windsor. 


\section{Nomenclature}

\begin{tabular}{|l|l|}
\hline $\mathrm{A}_{\mathrm{c}}$ & Channel cross section area, $\mathrm{m} 2$ \\
\hline Conv. & Conventional heat exchanger \\
\hline DAQ & Data Acquisition \\
\hline $\mathrm{L}$ & Channel length along the water fluid, $\mathrm{m}$ \\
\hline MICHX & Minichannel Heat Exchanger \\
\hline $\mathrm{MR}$ & Liquid inlet mass flow step ratio \\
\hline $\mathrm{n}$ & Number of channel \\
\hline PTD & Pressure Transducer and Transmitter \\
\hline RTD & Resistance Temperature Detector \\
\hline RSS & Root of sum of squares \\
\hline SCXI & Data acquisition module and terminal block \\
\hline $\mathrm{T}$ & Temperature, ${ }^{\circ} \mathrm{C}$ \\
\hline $\mathrm{TR}$ & Liquid inlet temperature step ratio \\
\hline $\mathrm{t}$ & Time, $\mathrm{s}$ \\
\hline $\mathrm{t}_{\mathrm{res}}$ & Resident time, $\mathrm{s}$ \\
\hline $\mathrm{V}$ & Velocity, $\mathrm{m} / \mathrm{s}$ \\
\hline $\mathrm{V}_{\mathrm{c}}$ & Velocity of liquid in the channel, $\mathrm{m} / \mathrm{s}$ \\
\hline$\dot{\forall}$ & Volume flow rate $\mathrm{m} 3 / \mathrm{s}$ \\
\hline
\end{tabular}

Subscripts

\begin{tabular}{|l|l|}
\hline c & Cold fluid \\
\hline i & Inlet \\
\hline h & Hot fluid, water stream \\
\hline o & Outlet \\
\hline
\end{tabular}

Superscripts

\begin{tabular}{|l|l|}
\hline$*$ & Dimensionless parameter \\
\hline$\infty$ & Steady state condition \\
\hline
\end{tabular}

\section{References}

[1] M. E. Steinke and S. G. Kandlikar, "Single-Phase Liquid. Heat Transfer in Plain and Enhanced Microchannels" Proceedings of ICNMM2006 Fourth International Conference on Nanochannels, Microchannels and Minichannels, Limerick, Ireland, 2006.

[2] S. Fotowat, M. Ismail, M. A. Quaiyum, S. Askar, and A. Fartaj, "Experimental study on air-heating through a crossflow minichannel heat exchanger," CSME Biennial International Conference, Winnipeg, Manitoba, Canada, 2012.

[3] D. J. Bunce, and S. G. Kandlikar, "Transient response of heat exchangers," in Proceedings of the 2nd ISHMT-ASME heat and mass transfer conference. Surathkal, India, 1995, pp. 729-736.

[4] K. Silaipillayarputhur, and S. A. Idem "Step response of a single-pass crossflow heat exchanger with variable inlet temperatures and mass flow rates" J Thermal Science and Engineering Applications, vol. 4, 044501 pp. 1-6, 2012.

[5] F. J. Stermole and M. A. Larson, "The dynamics of flow forced distributed parameter heat exchangers,) AIChE J., vol. 10, pp. 688-694, 1964.

[6] P. Regulagadda, "Transient Heat Transfer Analysis of Heat Exchangers in a Marnoch Heat Engine," Master thesis, Univ. of Ontario Institute of Technology, Oshawa, Ontario, 2009.

[7] F. Syed, and S. Idem "Transient Performance of a Cross Flow Heat Exchanger Using Finite Difference Analysis," ASME. ASME proceedings Heat Transfer, Fluid Flows, and Thermal Systems, Parts A, B, and C., vol. 10, pp. 1333$1342,2008$. 